\title{
Combined effects of predator cues and competition define habitat choice and food consumption of amphipod mesograzers
}

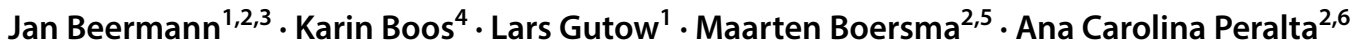

Received: 4 January 2017 / Accepted: 24 December 2017 / Published online: 15 January 2018

(c) The Author(s) 2018. This article is an open access publication

\begin{abstract}
Predation has direct impact on prey populations by reducing prey abundance. In addition, predator presence alone can also have non-consumptive effects on prey species, potentially influencing their interspecific interactions and thus the structure of entire assemblages. The performance of potential prey species may, therefore, depend on both the presence of predators and competitors. We studied habitat use and food consumption of a marine mesograzer, the amphipod Echinogammarus marinus, in the presence/absence of a fish mesopredator and/or an amphipod competitor. The presence of the predator affected both habitat choice and food consumption of the grazer, indicating a trade-off between the use of predator-free space and food acquisition. Without the predator, E. marinus were distributed equally over different microhabitats, whereas in the presence of the predator, most individuals chose a sheltered microhabitat and reduced their food consumption. Furthermore, habitat choice of the amphipods changed in the presence of interspecific competitors, also resulting in reduced feeding rates. The performance of E. marinus is apparently driven by trait-mediated direct and indirect effects caused by the interplay of predator avoidance and competition. This highlights the importance of potential non-consumptive impacts of predators on their prey organisms. The flexible responses of small invertebrate consumers to the combined effects of predation and competition potentially lead to changes in the structure of coastal ecosystems and the multiple species interactions therein.
\end{abstract}

Keywords Apparent competition · Trait-mediated interactions · Predator avoidance $\cdot$ Habitat segregation $\cdot$ Gammarus

Communicated by Pablo Munguia.

Electronic supplementary material The online version of this article (https://doi.org/10.1007/s00442-017-4056-4) contains supplementary material, which is available to authorized users.

Jan Beermann

Jan.Beermann@awi.de

1 Department of Functional Ecology, Alfred Wegener Institute, Helmholtz Centre for Polar and Marine Research, PO Box 120161, 27515 Bremerhaven, Germany

2 Alfred Wegener Institute, Helmholtz Centre for Polar and Marine Research, Biologische Anstalt Helgoland, Postbox 180, 27483 Helgoland, Germany

3 Helmholtz Institute for Functional Marine Biodiversity, Oldenburg, Germany

4 MARUM-Center for Marine Environmental Sciences, University of Bremen, Leobener Straße 8, 28359 Bremen, Germany

5 FB2, University of Bremen, Bremen, Germany

6 Marine Biology Laboratory, Simon Bolivar University, Caracas, Venezuela

\section{Introduction}

The global decline in populations of large predatory fish caused by overfishing and over-exploitation of local resources has contributed to an increase in populations of medium-sized predatory fish $(10-30 \mathrm{~cm})$ and crustaceans ('mesopredators') in marine systems (Myers and Worm 2003; Baum and Worm 2009; Eriksson et al. 2009). This process, referred to as 'mesopredator release' (cf. Eriksson et al. 2011), has resulted in a transition from large predator- to mesopredator-dominated systems in many marine areas (Baum and Worm 2009; Eriksson et al. 2011; Ory et al. 2012).

Marine mesograzers (i.e., small herbivorous invertebrates $\leq 2.5 \mathrm{~cm}$ ) are common prey organisms of mesoedators. Accordingly, many marine mesograzer communities are controlled by top-down processes, depending on the presence and diversity of predators (Douglass et al. 2008; Amundrud et al. 2015). Mesograzers affect macroalgal performance and productivity by grazing on algal thalli (negative effect) or by removing epiphytes (positive effect) (Andersson et al. 
2009). Therefore, mesoredators can influence macroalgal performance by controlling mesograzer abundance and thus grazing intensity (Davenport and Anderson 2007; Moksnes et al. 2008; Eriksson et al. 2009; Poore et al. 2014). Apart from the direct effect of predation (i.e., the decrease of prey abundance), indirect effects of the predators on mesograzer species might be equally or even more important. These non-consumptive effects of predator presence can alter interspecific interactions among prey species, thus driving the composition, abundance, and functioning of mesograzer communities (i.e., trait-mediated indirect effects; Paterson et al. 2013; Amundrud et al. 2015).

Shelter from predation could be more pivotal for a species than access to potential food sources and should concentrate animals in protected (micro) habitats (Best and Stachowicz 2012; Gutow et al. 2012; Whalen et al. 2013; Beermann and Boos 2015). Mesograzers often live in close association with seaweeds, and indeed, many species select their algal host for the protection it provides from predators (Buschmann 1990; Duffy and Hay 1991; Lancellotti and Trucco 1993; Sotka 2007; Lasley-Rasher et al. 2011). The aggregation of species in protective habitats may increase competition between mesograzer species and affect habitat use of cooccurring species. Therefore, habitat choice and feeding behavior of mesograzers within their algal refuges (and/ or the degree of habitat partitioning among species) might depend on both the presence of predators and competitors.

Amphipod crustaceans are common in algal assemblages and many species are effective mesograzers, exerting strong effects on algae (e.g., Duffy and Hay 2000; Andersson et al. 2009; Poore et al. 2012). Simultaneously, amphipods represent an important food source for predatory fish and larger invertebrates (Edgar and Shaw 1995; Moksnes et al. 2008; Pérez-Matus et al. 2012). For example, the omnivorous amphipod Echinogammarus marinus (Leach 1815) is frequently found on north-eastern Atlantic shores. The species inhabits dense algal assemblages in the upper intertidal zone, where it is subject to harsh environmental conditions (i.e., strong variation in salinity and temperature), but where fish predators are naturally less abundant (Vlasblom 1969; Van Maren 1975; Pinkster and Broodbakker 1980; Martins et al. 2014). The sympatric Gammarus locusta (Linnaeus 1758 ) is mostly associated with abundant algae in habitats from the lower intertidal and shallow subtidal zones to floating algal assemblages (Van Maren 1975; Andersson et al. 2009; Gutow et al. 2015). Hence, these species are spatially segregated in the field, but both amphipod species are effective mesograzers with similar preferences for food and habitat under predator- and competitor-free conditions (pers. obs.). The spatial segregation in the field may be a result of competitive exclusion, with E. marinus evading interspecific competition with $G$. locusta for predator-free space in favourable habitats. We thus hypothesize that the performance of E. marinus and its distribution in the field is driven by non-consumptive effects of predators and interspecific competition with sympatric gammarids. To test this hypothesis, we studied habitat use and food consumption of E. marinus in the presence/absence of predators and/or competitors. We first investigated single and combined effects of predator presence and interspecific competitor cues on $E$. marinus. In a second experimental setup, we tested for the effects of direct interference with a competitor and competitor density in the presence/absence of predator cues. The possible habituation of E. marinus to constant predator presence was investigated in a third experiment.

\section{Materials and methods}

\section{Animal collection and maintenance}

Approximately 1000 individuals of Echinogammarus marinus were collected in the rocky intertidal zone of the island of Helgoland (German Bight, North Sea; 54 $11^{\prime} 21^{\prime \prime} \mathrm{N}$; $7^{\circ} 52^{\prime} 60^{\prime \prime} \mathrm{E}$ ) in June and July 2015. Amphipods were collected from under flat rocks covered with canopies of the brown seaweed Fucus vesiculosus Linnaeus 1753. The specimens were maintained for 1 month under stable environmental conditions (flow-through of filtered seawater, average temperature of $16.5 \pm 0.5^{\circ} \mathrm{C}$, natural ambient light conditions) in a large aquarium ensuring a stock of animals large enough for experiments. The amphipods were fed thalli of F. vesiculosus. Individuals of Gammarus locusta were taken from a laboratory culture in a large aquarium under the exact same conditions as described above for E. marinus.

Approximately 50 individuals of the sea scorpion Taurulus bubalis (Euphrasen 1786) were collected with a bow net in Helgoland Harbor. The fish were kept in three separate aquaria $(50 \times 100 \times 45 \mathrm{~cm})$ for 2 weeks under stable environmental conditions $\left(15.0 \pm 0.5{ }^{\circ} \mathrm{C} ; 12 \mathrm{~h}\right.$ light: $12 \mathrm{~h}$ darkness) in a flow-through system with filtered seawater. Until being used in the experiments, the fish were fed a diet of live E. marinus, which were actively chased and eagerly eaten by the fish.

\section{General experimental setup}

The following setup was employed for all experimental treatments: small transparent plastic aquaria (8 1; $32.5 \times 17.5 \times 18.5 \mathrm{~cm}$ ) were each supplied with a uni-directional flow-through system of filtered seawater of approx. $800 \mathrm{~mL} / \mathrm{min}$. All experiments were conducted under constant laboratory conditions (average temperature of $16.5 \pm 0.5^{\circ} \mathrm{C}$; $12 \mathrm{~h}$ light: $12 \mathrm{~h}$ darkness). Each aquarium was divided in half by a plastic mesh (mesh size $1 \mathrm{~mm}$ ). The posterior half of the aquarium, opposite to the entry of the water flow, was supplied 
with a thallus of the macroalga $F$. vesiculosus (biomass: $700 \mathrm{mg})$ and a slightly sloping ceramic tile $(10 \times 10 \mathrm{~cm})$, providing a hiding place similar to flat stones in the field (Fig. 1). To test the influence of the presence of a potential predator, a single specimen (ca. $10 \mathrm{~cm}$ body length) of T. bubalis was placed in the anterior half of the aquarium. The seawater flow was directed from the fish towards the amphipods. During the experiment, the fish were not fed, preventing that cues of wounded conspecifics may have affected the behavior of the amphipods.

In all experiments, groups of 20 individuals of E. marinus of similar size (18 $\pm 2 \mathrm{~mm}$ body length) were placed in the aquaria and starved for $24 \mathrm{~h}$ to standardize hunger levels among individuals. The experiments were then started with the addition of the algae and, where applicable, the individual predators to the setups. After $24 \mathrm{~h}$, the position of each individual amphipod was assessed at daytime without manipulating the container. Five different habitats were distinguished: (1) on the algal thallus; (2) under the tile; (3) clinging to the mesh that separated the aquarium; (4) attached to a wall of the aquarium, touching the water surface, and/or leaving the water partly or completely; and (5) any remaining part of the aquarium. Dead individuals were recorded.

After the non-manipulative assessment, the algae were removed from the setups and their wet weights were measured. The resulting feeding rates in the different experimental setups were calculated by the following equation (see Cronin and Hay 1996):

feeding rate $=\left[\left(\mathrm{Wi} \times \frac{\mathrm{Cf}}{\mathrm{Ci}}\right)-\mathrm{Wf}\right] \times \mathrm{day}^{-1}$.
Initial (Wi) and final weight (Wf) of the thallus were measured before and after each experiment. For each experiment, controls without any animals were run in five separate aquaria (cf/ci) to control for autogenic weight change of the algae. All weights were measured by blotting the thalli on laboratory paper to remove any surface water.

Five replicates (aquaria) were conducted per treatment for each experimental setup. Each amphipod and fish predator was used only once.

\section{Presence of a predator and interspecific competitors}

In a first experiment, food consumption and habitat utilization of $E$. marinus were tested in the presence and absence of the fish predator T. bubalis and the competitor G. locusta in a full-factorial design. Groups of five individuals of $G$. locusta $(13 \pm 1 \mathrm{~mm}$ body length) were placed in small cages without food $(7 \times 5 \times 5 \mathrm{~cm})$. One cage was deployed in each aquarium in the same halves as E. marinus. The cages clearly separated $G$. locusta from the experimental animals, thus preventing direct interference between hetero-specific individuals. After $24 \mathrm{~h}$, habitat utilization and feeding rates were evaluated as described above.

\section{Direct interference effect}

A second experiment tested for the effects of direct interference on habitat choice and food consumption of E. marinus in the presence of the predator T. bubalis. Three different treatments, with groups of 5, 10, and no individuals of $G$. locusta (same size class: $13 \pm 1 \mathrm{~mm}$ ), were placed without

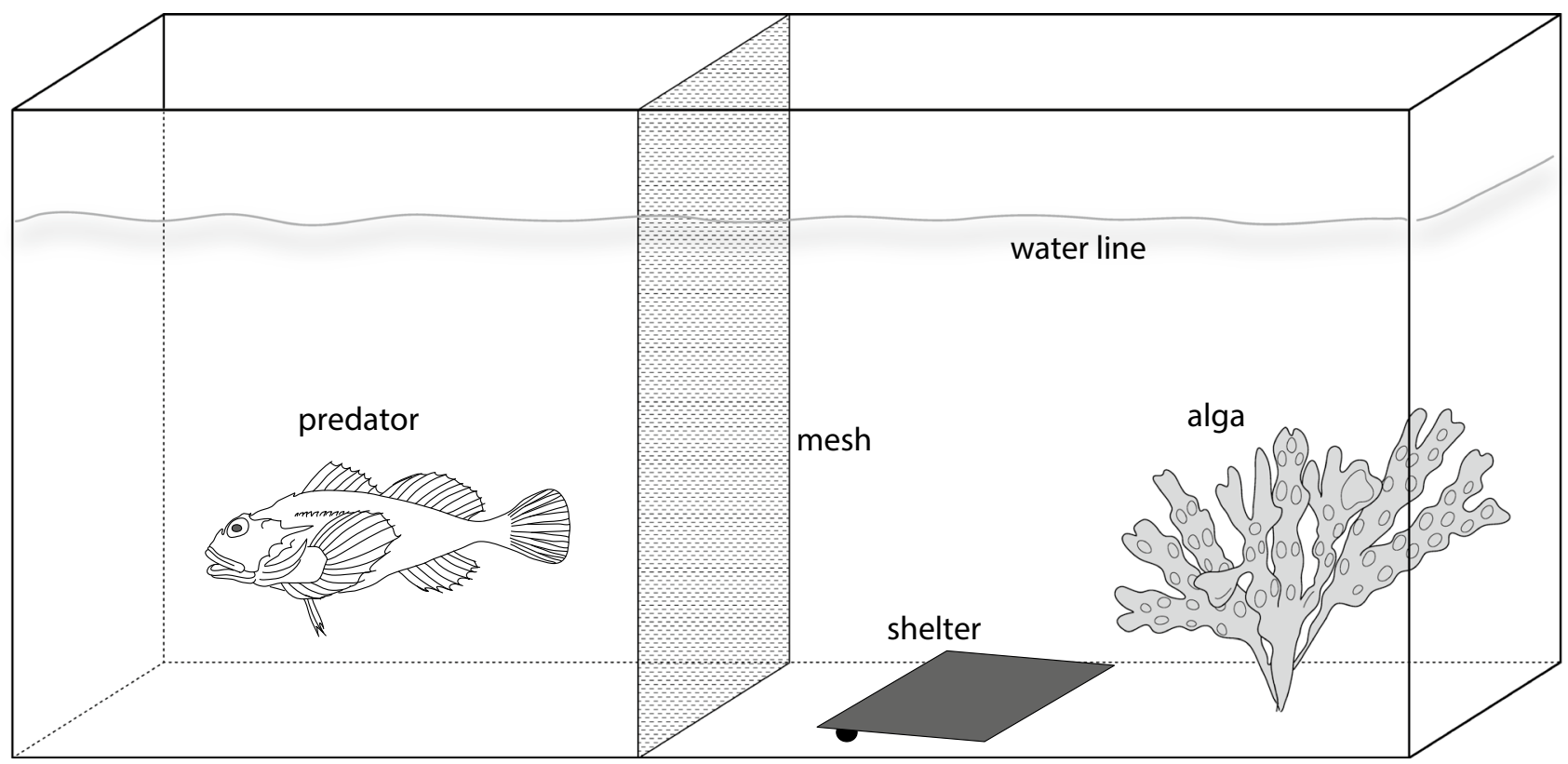

Fig. 1 General experimental setup for the investigation of habitat choice and food consumption in the amphipod Echinogammarus marinus 
cages, thus allowing for direct encounter between individuals of the two species. After $24 \mathrm{~h}$, the position of each $E$. marinus was registered. As both species were feeding on the same algal thalli and the group sizes were unequal, per capita feeding rates were calculated for both single-species and mixed-species setups by dividing the overall food consumption by the total number of amphipods ( $E$. marinus and G. locusta) employed in the respective setups.

\section{Habituation to predator presence}

A third experiment tested for possible habituation of $E$. marinus to the fish cue stimulus. Habitat utilization and food consumption of $E$. marinus were measured as described above every $24 \mathrm{~h}$ over a total period of $96 \mathrm{~h}$. After each measurement, both the algal thalli and the T. bubalis individuals were replaced by new specimens. This minimized possible aging effects of the algae, ensured a steady food supply for the amphipods, and prevented any negative effects on the fish that could have also affected the amphipods' behavior. Dead individuals of E. marinus were not replaced.

\section{Statistical analyses}

Two response variables ('habitat choice' and 'food consumption') were measured in each of the three experiments. For the first experiment ('predator and competitor cues'), a multivariate approach was used to analyze the response variable 'habitat choice'. We modelled the individual habitats as counts (i.e., shares) of individuals in multiple categories (i.e., 'shelter', 'algae', 'mesh', 'waterline', and 'remaining areas') with multinomial regression analyses. This type of analyses was most appropriate, because it accounts for the dependent nature of the data in multiple choice designs. Furthermore, the respective sizes of the habitats each provided sufficient space to harbor much more than all employed animals at once, thus ensuring that the individuals could perform choice behaviors independent of animal density. In addition, we found no indication for gregarious behavior in preliminary experiments. Occasionally, individuals were found dead after an experimental trial. In those cases, the number of perished animals was modelled for technical reasons as an additional choice category. The multivariate model included the fixed factor 'predator' with the two levels absent and present. In addition, the model for the first experiment included the fixed factor 'competitor' with two levels (absent and present). The model included the interaction between the two main terms.

The response variable 'food consumption' was analyzed using a general linear model (LM) with a fully crossed twoway design. The predictor variables in this univariate model were the same as for the habitat choice analyses, including the interaction.

To confirm the assumptions of normally distributed and homogenous residuals, qq plots and the residuals plotted against the fitted values were visually inspected (Quinn and Keough 2002). In cases where the assumptions were not met, the data were log transformed to fulfill the criteria.

To establish the significances of individual terms (interaction terms and main factors), likelihood ratio tests (LRT; using $\mathrm{F}$ tests in the fixed models and $\mathrm{Chi}^{2}$ tests in the mixed model) were used to compare the residual sum of squares of the respective full models with those of the corresponding reduced models not comprising the respective factor and/or term of interest. For intuitive interpretations of the response variable 'habitat choice', we calculated the predicted probabilities (fitted values in \%) for each category outcome (i.e., habitat type) across predictor levels (i.e., absence or presence of the predator and/or competitor, respectively). This was done using the 'predict' function (in the software R; see below) on the individual model coefficients for all combinations.

For the second experiment ('direct interference'), the response variable 'habitat choice' was analyzed using the same multivariate approach as for the first experiment including the fixed factor 'competitor' with three abundance levels (absent, 5 individuals, and 10 individuals). The response variable ‘food consumption' was analyzed using the same general linear model (LM) with a fully crossed two-way design as in the first experiment.

For the third experiment ('habituation'), the response variable 'habitat choice' was analyzed using the same multivariate model as for the first and second experiments. 'Time' was included as continuous fixed effects factor into the model and a random within-subjects factor was incorporated as a random term, where replicate was nested in time. For the interpretations, we averaged the predictions for all replicates. The response variable 'food consumption' was analyzed using a general linear mixed model (LMM) with a repeated measures design (within-subjects factor). The predictor variables in the univariate model were the same as described before, including the interactions and with the additional random within-subjects factor. To establish the significances of individual terms (interaction terms and main factors), LRTs using $\mathrm{Chi}^{2}$ tests for both the multivariate model and the mixed model were applied.

All models were fitted in $\mathrm{R}$, version 3.2.2 ( $\mathrm{R}$ Development Core Team 2015), using the generic function ' $1 \mathrm{~m}$ ', the 'lmer' function from the 'lme4' package (Bates et al. 2015) for the food consumption analyses and the 'multinom' function from the 'nnet' package (Venables and Ripley 2002) for the habitat choices. 


\section{Results}

\section{Presence of a predator and interspecific competitors}

The comparisons of the animals' habitat utilizations revealed no interaction of the factor 'predator' and the presence of a competitor $\left(\mathrm{LRT}_{\text {competitor:predator: }} \chi^{2}\right.$ (5) $=0.0108 ; p=0.9999)$. Similarly, the presence of competitors alone did not affect animals' habitat choice $\left(\mathrm{LRT}_{\text {competitor }}: \chi^{2}(5)=4.9724 ; p=0.4192\right)$. However, the presence of the fish predator had a clear effect on habitat utilization of Echinogammarus marinus (LRT predator $\chi^{2}$ (5) $=163.2095 ; p<0.0001)$, independent of the presence of the competitor. In the absence of predators, the combined predicted probability of finding individuals on the mesh or on the algal thallus was $43 \%$, whereas the probability to find animals in the shelter was $47 \%$. In the presence of a predator, however, the amphipods were largely confined to the shelter below the tile (probability: 90\%) with a low but increased probability of $6 \%$ to be found near the water line (Fig. 2a).

The two factors also showed no significant interactive effect on the consumption rate ( $\mathrm{LRT}_{\text {competitor:predator: }}$ $\left.F_{1,16}=0.0854 ; p=0.7738\right)$. The presence of the predator alone, however, had a strong effect on food consumption of the amphipods (LRT predator $: F_{1,18}=92.9360$; $p<0.0001$ ), which clearly decreased when the predator was present in both trials (Fig. 2b). The average feeding rates were slightly lower in the presence of the competitor, although this was not statistically significant (LRT competitor: $\left.F_{1,18}=3.4675 ; p=0.0799\right)$. Thus, the presence of predators affected behavior and grazing, whereas the presence of competitors did not.

\section{Direct interference effect}

In the presence of a predator and in direct interference with the potential competitor, there was a significant interaction in the habitat use of $E$. marinus [LRT competitor:predator: $\left.\chi^{2}(8)=20.5699 ; p=0.0083\right]$. Moreover, the animals' habitat choice, again, strongly depended on the presence of the fish predator [LRT predator $: \chi^{2}(4)=112.0918$; $p<0.0001]$ and on the direct contact with the competitor [LRT competitor: $\left.\chi^{2}(8)=56.1650 ; p<0.0001\right]$. As before, in the presence of the predator, the amphipods had a stronger preference for the shelter in all trials. However, the predicted probabilities for finding animals in the shelter decreased with increasing competitor density from $91 \%$ (competitor absent) to 56\% (10 competitors) (Fig. 3a). At the same time (i.e., in the presence of the predator), the combined probabilities to find E. marinus on the mesh or (a)

Presence of predator and competitors

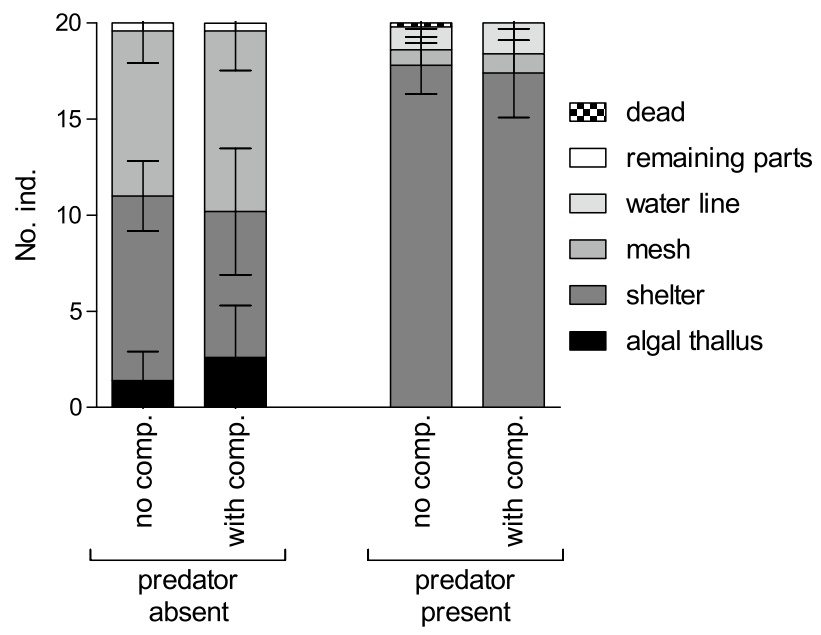

(b)

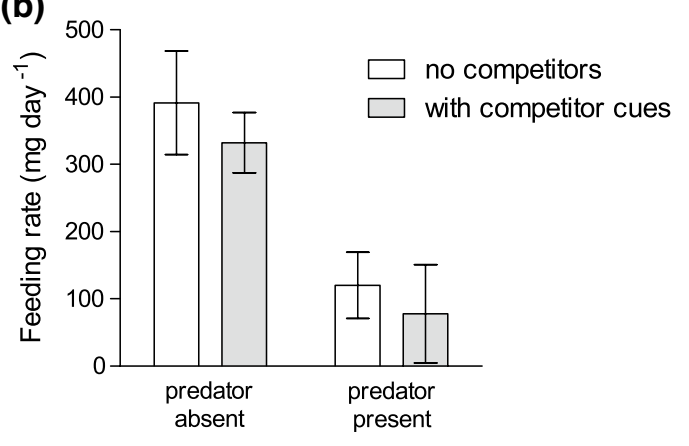

Fig. 2 Spatial distribution (a) and food consumption (b) of groups of 20 individuals each of Echinogammarus marinus in the presence of the predator Taurulus bubalis and with cues of the congeneric competitor Gammarus locusta. Note that only a single dead individual was found; mean $\pm \mathrm{SD}($ each $N=5)$

on the algal thallus increased from 5\% (competitor absent) to $12 \%$ (5 competitors) and even $37 \%$ (10 competitors). In the trials, G. locusta was mainly found in the shelter, but never on the algal thallus (see Fig. S1 in the Electronic Supplement).

In the absence of a predator, the amount of algal tissue that was consumed by E. marinus (single-species trial) or both species (in the two mixed-species trials), respectively, slightly decreased on average with increasing density of the competitor G. locusta, whereas feeding rates remained similarly low for all competitor densities when a predator was present (Fig. 3b). However, due to high variability in the data, the differences in feeding rates were statistically not significant (LRT competitor:predator: $_{2,24}=1.3127 ; p=0.2877$ ), also leading to no effect of competition (LRT competitor: : $\left.F_{2,27}=0.5366 ; p=0.5911\right)$. The presence of a predator clearly reduced the food consumption in all treatments (LRT predator: $\left._{1,28}=26.4800 ; p<0.0001\right)$. Thus, habitat choice was affected by the actual presence of competitors, 
(a) Direct interference

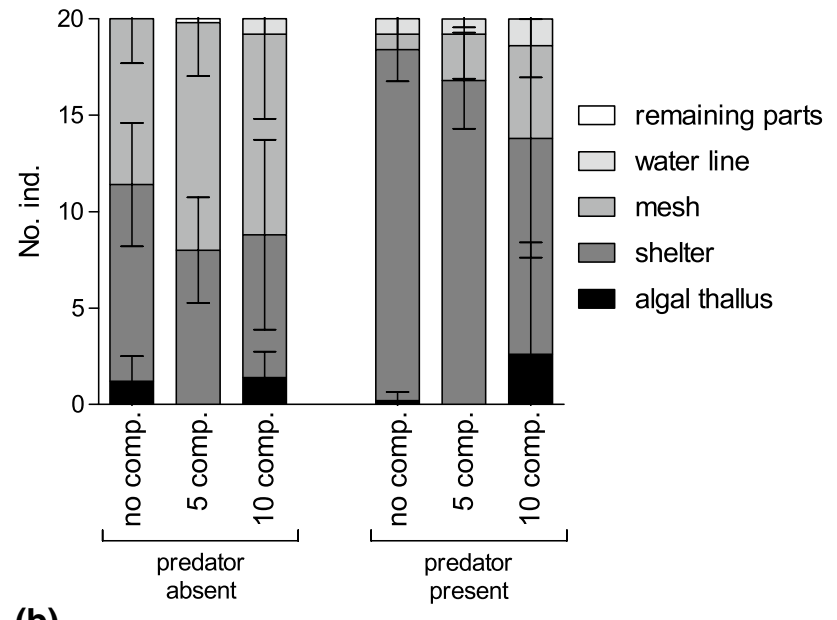

(b)

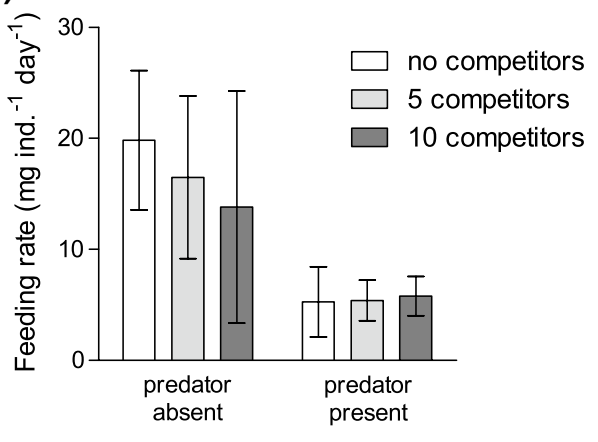

Fig. 3 Spatial distribution (a) and per capita food consumption (b) of groups of 20 individuals each of Echinogammarus marinus in direct interaction with groups (5 or 10 individuals each) of Gammarus locusta and in the presence of the predator Taurulus bubalis; mean $\pm \mathrm{SD}$ (each $N=5$; no mortality occurred). Note that for the single-species trials (without competitor), the consumption rates were calculated for E. marinus only, whereas for the mixed-species trials (with the competitor $G$. locusta), the combined consumption rates were calculated considering the individuals of both species

but this was not reflected in the combined consumption rates of the two species.

\section{Habituation to predator presence}

The reaction in habitat choice to predator cues was independent of time over the entire experimental period of $96 \mathrm{~h}$ $\left[\mathrm{LRT}_{\text {time:predator }}: \chi^{2}(5)=4.0488 ; p=0.5424\right]$. The amphipods responded to the predator cue treatment [LRT $\mathrm{Lredator}$ : $\left.\chi^{2}(5)=185.7960 ; p<0.0001\right]$ and the general patterns remained the same over time (Fig. 4a): in the absence of the predator, the predicted probabilities to find individuals in the shelter or on the mesh were similar (between 47-49 and $42-48 \%$, respectively), whereas probabilities to find individuals in the shelter remained high (81-84\%) when the predator was present. However, the increase in dead individuals (Fig. 4a) over the duration of the experiment $(1.8 \pm 1.09$

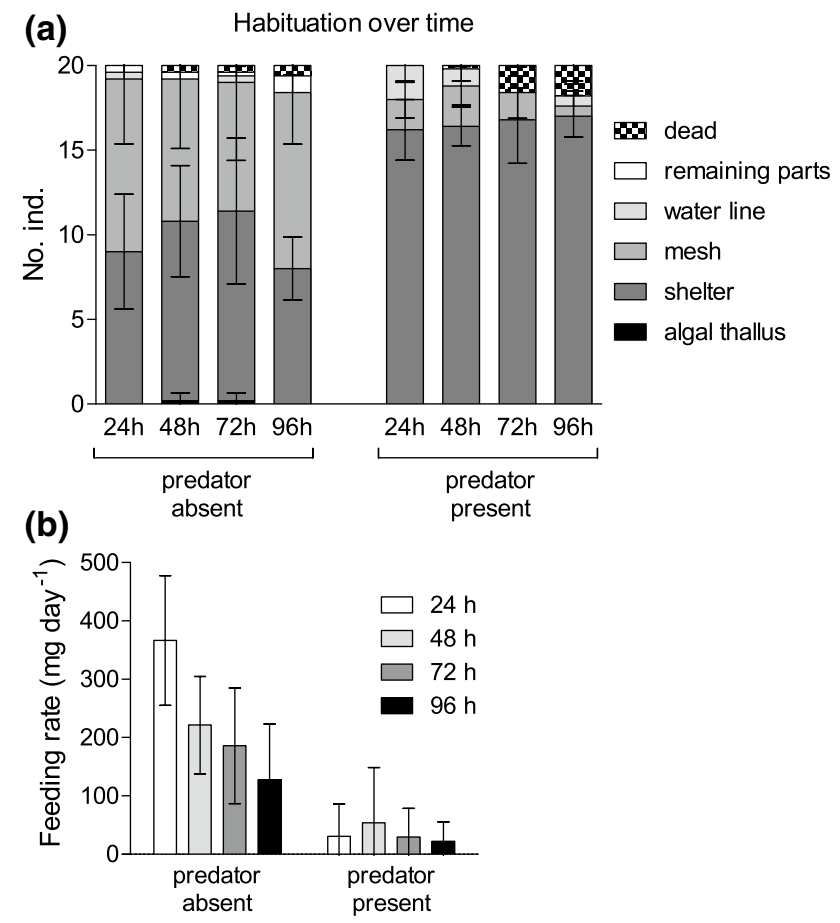

Fig. 4 Spatial distribution (a) and food consumption (b) of groups of 20 individuals each of Echinogammarus marinus over the consecutive duration of $24,48,72$, and $96 \mathrm{~h}$ in the presence of the predator Taurulus bubalis; mean $\pm \mathrm{SD}($ each $N=5)$

individuals after $96 \mathrm{~h}$ ) resulted in a significant effect of the main factor 'time' [ $\left.\mathrm{LRT}_{\text {time }}: \chi^{2}(5)=24.8737 ; p<0.0001\right]$.

In the absence of a predator, feeding rates decreased over time, whereas the consumed amounts in the presence of a predator were consistently low $\left[\mathrm{LRT}_{\text {time:predator }}: \chi^{2}\right.$ $(1)=7.2290 ; p=0.0071 ;$ Fig. $4 \mathrm{~b}]$. Overall, the feeding rate was consistently lower in the presence of the fish predator [LRT predator $\left.\chi^{2}(1)=13.9900 ; p=0.0002\right]$.

See the Electronic Supplementary Data (Tables S1, S2) for the full results of the statistical analyses.

\section{Discussion}

\section{Predator presence}

The presence of a fish mesopredator clearly affected both habitat choice and feeding activity of Echinogammarus marinus, indicating a trade-off between shelter and food acquisition. In the absence of the predator, some amphipods were found associated with the algae which served as food for the animals. In contrast, in the presence of a predator and in the absence of direct interference with competitors, the individuals completely avoided the algal thalli and hid below the ceramic tile, where, under field conditions, they would probably be less easily accessible for larger fish predators. 
Apparently, the amphipods preferred shelter over food under the risk of predation. In the current setups, however, the habitat choice of the animals was evaluated at daytime only. Feeding and possible behavioral responses to predator cues probably differ in their level of intensity and manifestation during night time (Szokoli et al. 2015). Amphipods probably leave protective habitats preferably at night to forage on food algae (Buschmann 1990). Accordingly, the observed patterns of habitat use may be an underestimation of the actual use of the algal habitat by $E$. marinus. The obtained consumption of algal biomass indicates a frequent and extensive association with the algal habitat at night when the amphipods are protected from visually hunting predators. However, food consumption of the amphipods decreased in the presence of the predator. This response has also been observed in other marine amphipods (Reynolds and Sotka 2011; Reynolds and Bruno 2013). The reduced feeding activity may be the consequence of spatial segregation from the food source, because the animals spent more time under the protective tile (Lima and Dill 1990), or a direct behavioral response to the predator presence (Alexander et al. 2013).

Common reactions to predator cues by aquatic crustaceans involve the search for refuge (i.e., complex structures, shelter), reduction of activity, association with chemically defended algae, withdrawal from the predator, and/or emigration to predator-free patches (e.g., Thiel and Reise 1993; Abjörnsson et al. 2000; Lindén et al. 2003; van Son and Thiel 2006; Zamzow et al. 2010; Beermann and Boos 2015). In contrast to our current findings, E. marinus did not change its habitat use, but reduced its movement activity in experiments with a different fish mesopredator, the shanny Lipophrys pholis (Alexander et al. 2013). This indicates predator-specific avoidance behaviors (e.g., McIntosh and Peckarsky 1999; Abjörnsson et al. 2000; van Son and Thiel 2006). Similarly, the avoidance behavior of the amphipods in our experiments could be a specific reaction to the particular cues released by Taurulus bubalis. Some amphipods respond to the presence of benthic predators with emigration (e.g., Thiel and Reise 1993; van Son and Thiel 2006). The role of emigration in the predator avoidance of $E$. marinus cannot be evaluated from our laboratory setups, where the amphipods had no opportunity to emigrate. The presence of fish, however, mostly induces use of sheltered (micro) habitats that are less accessible to these predators (Thiel and Reise 1993; Abjörnsson et al. 2000; van Son and Thiel 2006; Beermann and Boos 2015), indicating that hiding in a sheltered habitat may likely represent the primary response of E. marinus to the presence of T. bubalis. Alternatively, an enhanced presence of the amphipods near the waterline or in the remaining parts of the container probably could be an indication for an attempted emigration. In natural habitats, further parameters, such as habitat quality and competition, may also influence prey reactions along with other cues such as signals of actual predation (i.e., cues of wounded conspecifics; Baumgärtner et al. 2003; Pennuto and Keppler 2008; Beermann and Boos 2015).

Some peracarid crustaceans have been shown to habituate to a constant stimulus of fish cues (e.g., Holomuzki and Hatchett 1994). However, the reaction of E. marinus to the predator did not change over the entire duration of 4 days. This supports the conclusion of Patterson et al. (2013) from a meta-analysis that both the intensity and the exposure time to fish cues have only little to no effect on the overall prey response. The duration of the current experiment may have been too short to observe long-term habituation to the stimulus as suggested by experiments of longer duration on freshwater amphipods (see Abjörnsson et al. 2000). A flexible response to predator presence may be an important adaptation to changing environmental conditions and/or constant threats of predation (Beermann and Boos 2015). The spatial distribution of E. marinus in the field (i.e., under stones and rocks in the intertidal) could thus be a response to the constant stimulus of predator cues, whereas in the laboratory, the animals did not seem to seek for such habitats in the absence of predators.

Interestingly, the feeding rates of E. marinus decreased over the 4 days in the predator-free setups of the third experiment, whereas in the presence of the predator, the feeding rates were consistently low. This decrease may reflect a shift from excessive feeding after the initial starvation period at the beginning of the experiment towards a more normal feeding behavior when the animals had unlimited access to food.

\section{Competitor presence}

The direct presence of a competitor affected the habitat choice of the amphipods. In mixed-species trials together with Gammarus locusta, E. marinus was less likely to be found in the shelter as compared to the single-species trials. This was particularly pronounced in the presence of predator cues. In addition, food consumption was slightly lower in the presence of the competitor or even when E. marinus was just exposed to competitor cues. The mixed-species setups did not allow discriminating between the specific consumption rates of E. marinus and G. locusta. The pooled consumption rates of the two species must, therefore, be regarded with caution as one of the two species may have consumed on average much more algal material than the other. The slightly reduced combined food consumption of the amphipods in the presence of interspecific competitors, however, was not the result of competition for food between the two amphipod species, because algal food was not limited in the experiments. Similarly, natural mesoherbivore communities inhabit extensive macroalgal beds which provide plenty and diverse food for numerous small consumers 
(Taylor 1998). Alternatively, the reduced consumption may be a direct effect of interspecific interference competition (e.g., Persson 1986). Furthermore, predator presence may induce 'apparent competition' among species (also called 'competition for enemy-free space'; Holt 1977) which has similar implications as competition for food resources. Interference between the animals could, therefore, have hindered the amphipods from feeding, even displacing E. marinus to less protected habitats under the threat of predation. This is corroborated by the observed microhabitat preferences of $G$. locusta in the experiments that clearly preferred the shelter over the other habitats in the container (Fig. S1 in the Electronic Supplement).

Persistently strong competition for shelter due to an elevated predation risk may result in competitive exclusion, unless mechanisms such as habitat partitioning reduce the intensity of competition, thereby allowing for a coexistence of species (Schoener 1974, 1986). This type of habitat partitioning is most likely to evolve among frequently co-occurring species. Accordingly, animal species respond flexibly to the presence of competitors (e.g., Ebersole 1985; Beermann and Boos 2015) or exhibit predetermined preferences, leading to a partitioning of resources (e.g., Ebersole 1985; Lürig et al. 2016). Apparently, competition for shelter increased among the competitors (i.e., increased 'apparent competition'). The observed distributional patterns thus indicate that (1) G. locusta is competitively superior, as it displaced individuals of $E$. marinus from the shelter that was preferred by both species (c.f. Jermacz et al. 2015) and/ or (2) E. marinus is able to respond flexibly to reduce competition with other gammarids. Consequently, under natural conditions, an apparent competition probably results in a higher predation risk for E. marinus. This is corroborated by the distribution pattern of the two species in the field: $G$. locusta occupies a wider range of habitats, whereas E. marinus is mainly restricted to intertidal and euryhaline habitats, where the species may have a competitive advantage due to its higher tolerances to harsh environmental conditions (Van Maren 1975; Pinkster and Broodbakker 1980).

\section{Conclusions}

Trait-mediated indirect interactions with mesopredators may either be positive (mesograzer activity reduction) or negative for certain algae species (habitat shift of mesograzers to particular algal species) (Schmitz et al. 2004). Simultaneously, intensity and nature of intraguild interactions may largely depend on the degree of predation pressure, because an increased aggregation of prey species at 'safe' sites likely modifies competitive relationships (i.e., trait-mediated indirect interactions; Holt 1984; Pallini et al. 1998; Werner and Peacor 2003). In our model system, the performance of $E$. marinus is determined by trait-mediated direct and indirect effects caused by the presence of predators and competitors. As the fish presence affected the food consumption of the amphipods, the presence of mesoredators should have a positive trait-mediated indirect effect on algae in addition to the direct effects of predation on the mesograzers. Consequently, a mesopredator release can have strong non-consumptive impacts on mesograzer performance. Substantial changes in the structure and composition of marine species assemblages in coastal ecosystems could be a consequence.

Acknowledgements ACP was financially supported by the Nippon Foundation-POGO Centre of Excellence. We thank Markus Molis (AWI) for the friendly loan of aquarium systems and Prof. Werner Wosniok for constructive discussions on the statistical analyses. Martin Thiel and an anonymous reviewer provided constructive comments on earlier versions of the manuscript, greatly improving its quality.

Author contribution statement JB, MB, and ACP designed the experiments and developed the methodology. ACP and JB performed the experiments. $\mathrm{KB}$ and JB analyzed the Data. JB, LG, and KB wrote the manuscript with editorial advice by the other authors.

\section{Compliance with ethical standards}

Ethical approval All applicable institutional and/or national guidelines for the care and use of animals were followed.

Open Access This article is distributed under the terms of the Creative Commons Attribution 4.0 International License (http://creativecomm ons.org/licenses/by/4.0/), which permits unrestricted use, distribution, and reproduction in any medium, provided you give appropriate credit to the original author(s) and the source, provide a link to the Creative Commons license, and indicate if changes were made.

\section{References}

Abjörnsson K, Dahl J, Nyström P, Brönmark C (2000) Influence of predator and dietary chemical cues on the behaviour and shredding efficiency of Gammarus pulex. Aquat Ecol 34:379-387

Alexander ME, Dick JTA, O'Connor NE (2013) Trait-mediated indirect interactions in a marine intertidal system as quantified by functional responses. Oikos 122:1521-1531

Amundrud SL, Srivastava DS, O'Connor MI (2015) Indirect effects of predators control herbivore richness and abundance in a benthic eelgrass (Zostera marina) mesograzer community. J Anim Ecol 84:1092-1102

Andersson S, Persson M, Moksnes P-O, Baden S (2009) The role of the amphipod Gammarus locusta as a grazer on macroalgae in Swedish seagrass meadows. Mar Biol 156:969-981

Bates D, Maechler M, Bolker B, Walker S (2015) Fitting linear mixedeffects models using lme4. J Stat Softw 67:1-48

Baum JK, Worm B (2009) Cascading top-down effects of changing oceanic predator abundances. J Anim Ecol 78:699-714

Baumgärtner D, Koch U, Rothaupt K-O (2003) Alteration of kairomone-induced antipredator response of the freshwater amphipod Gammarus roeseli by habitat. J Chem Ecol 29:1391-1401 
Beermann J, Boos K (2015) Flexible microhabitat partitioning between hemi-sessile congeners. Mar Ecol Prog Ser 520:143-151

Best RJ, Stachowicz JJ (2012) Trophic cascades in seagrass meadows depend on mesograzer variation in feeding rates, predation susceptibility, and abundance. Mar Ecol Prog Ser 456:29-42

Buschmann AH (1990) Intertidal macroalgae as refuge and food for Amphipoda in central Chile. Aquat Bot 36:237-245

Cronin G, Hay ME (1996) Induction of seaweed chemical defenses by amphipod grazing. Ecology 77:2287-2301

Davenport AC, Anderson TW (2007) Positive indirect effects of reef fishes on kelp performance: the importance of mesograzers. Ecology 88:1548-1561

Douglass JG, Duffy JE, Bruno JF (2008) Herbivore and predator diversity interactively affect ecosystem properties in an experimental marine community. Ecol Lett 11:598-608

Duffy JE, Hay ME (1991) Food and shelter as determinants of food choice by an herbivorous marine amphipod. Ecology 72:1286-1298

Duffy JE, Hay ME (2000) Strong impacts of grazing amphipods on the organization of a benthic community. Ecol Monogr 70:237-263

Ebersole JP (1985) Niche separation of two damselfish species by aggression and differential microhabitat utilization. Ecology 66:14-20

Edgar GJ, Shaw C (1995) The production and trophic ecology of shallow-water fish assemblages in southern Australia II. Diets of fishes and trophic relationships between fishes and benthos at Western Port, Victoria. J Exp Mar Biol Ecol 194:83-106

Eriksson BK et al (2009) Declines in predatory fish promote bloomforming macroalgae. Ecol Appl 19:1975-1988

Eriksson BK et al (2011) Effects of altered offshore food webs on coastal ecosystems emphasize the need for cross-ecosystem management. Ambio 40:786-797

Gutow L et al (2012) Herbivorous amphipods inhabit protective microhabitats within thalli of giant kelp Macrocystis pyrifera. Mar Biol 159:141-149

Gutow L, Beermann J, Buschbaum C, Rivadeneira MM, Thiel M (2015) Castaways can't be choosers-homogenization of rafting assemblages on floating seaweeds. J Sea Res 95:161-171

Holomuzki JR, Hatchett LA (1994) Predator avoidance costs and habituation to fish chemicals by a stream isopod. Freshw Biol 32:585-592

Holt RD (1977) Predation, apparent competition, and the structure of prey communities. Theor Popul Biol 12:197-229

Holt RD (1984) Spatial heterogenity, indirect interactions, and the coexistence of prey species. Am Nat 124:377-406

Jermacz L, Dzierzynska A, Kakareko T, Poznanska M (2015) The art of choice: predation risk changes interspecific competition between freshwater amphipods. Behav Ecol 26:656-664

Lancellotti DA, Trucco RG (1993) Distribution patterns and coexistence of six species of the amphipod genus Hyale. Mar Ecol Prog Ser 93:131-141

Lasley-Rasher RS, Rasher DB, Marion ZH, Taylor RB, Hay ME (2011) Predation constrains host choice for a marine mesograzer. Mar Ecol Prog Ser 434:91-99

Lima SL, Dill LM (1990) Behavioral decisions made under the risk of predation: a review and prospectus. Can J Zool 68:619-640

Lindén E, Lehtiniemi M, Viitasalo M (2003) Predator avoidance behaviour of Baltic littoral mysids Neomysis integer and Praunus flexuosus. Mar Biol 143:845-850

Lürig MD, Best RJ, Stachowicz JJ (2016) Microhabitat partitioning in seagrass mesograzers is driven by consistent species choices across multiple predator and competitor contexts. Oikos 125:1324-1333

Martins I, Leite N, Constantino E (2014) Consumption and feeding preference of Echinogammarus marinus on two different algae: Fucus vesiculosus and Ulva intestinalis. J Sea Res 85:443-446
McIntosh AR, Peckarsky BL (1999) Criteria determining behavioural responses to multiple predators by a stream mayfly. Oikos 85:554-564

Moksnes P-O, Gullström M, Tryman K, Baden S (2008) Trophic cascades in a temperate seagrass community. Oikos 117:763-777

Myers RA, Worm B (2003) Rapid worldwide depletion of predatory fish communities. Nature 423:280-283

Ory NC, Dudgeon D, Dumont CP, Miranda L, Thiel M (2012) Effects of predation and habitat structure on the abundance and population structure of the rock shrimp Rhynchocinetes typus (Caridea) on temperate rocky reefs. Mar Biol 159:2075-2089

Pallini A, Janssen A, Sabelis MW (1998) Predators induce interspecific herbivore competition for food in refuge space. Ecol Lett 1:171-177

Paterson RA, Pritchard DW, Dick JTA, Alexander ME, Hatcher MJ, Dunn AM (2013) Predator cue studies reveal strong trait-mediated effects in communities despite variation in experimental designs. Anim Behav 86:1301-1313

Pennuto C, Keppler D (2008) Short-term predator avoidance behavior by invasive and native amphipods in the Great Lakes. Aquat Ecol 42:629-641

Pérez-Matus A, Pledger S, Díaz FJ, Ferry LA, Vásquez JA (2012) Plasticity in feeding selectivity and trophic structure of kelp forest associated fishes from northern Chile. Rev Chil Hist Nat $85: 29-48$

Persson L (1986) Effects of reduced interspecific competition on resource utilization in perch (Perca fluviatilis). Ecology 67:355-364

Pinkster S, Broodbakker NW (1980) The influence of environmental factors on distribution and reproductive success of Eulimnogammarus obtusatus (Dahl, 1938) and other estuarine gammarids. Crustaceana Suppl 6:225-241

Poore AGP et al (2012) Global patterns in the impact of marine herbivores on benthic primary producers. Ecol Lett 15:912-922

Poore AGP, Gutow L, Pantoja JF, Tala F, Madariaga DJ, Thiel M (2014) Major consequences of minor damage: impacts of small grazers on fast-growing kelps. Oecologia 174:789-801

Quinn GGP, Keough MJ (2002) Experimental design and data analysis for biologists. Cambridge University Press, Cambridge

R Development Core Team (2015) R: a language and environment for statistical computing. R Foundation for statistical computing, Vienna, Austria https://wwwR-project.org

Reynolds PL, Bruno JF (2013) Multiple predator species alter prey behavior, population growth, and a trophic cascade in a model estuarine food web. Ecol Monogr 83:119-132

Reynolds PL, Sotka EE (2011) Non-consumptive predator effect indirectly influence marine plant biomass and palatability. J Ecol 99:1272-1281

Schmitz OJ, Krivan V, Ovadia O (2004) Trophic cascades: the primacy of trait-mediated indirect interactions. Ecol Lett 7:153-163

Schoener TW (1974) Resource partitioning in ecological communities. Science 185:27-39

Schoener TW (1986) Resource partitioning. In: Kikkawa J, Anderson DK (eds) Community ecology: patterns and process. Blackwell, Melbourne, pp 91-126

Sotka EE (2007) Restricted host use by the herbivorous amphipod Peramphithoe tea is motivated by food quality and abiotic refuge. Mar Biol 151:1831-1838

Szokoli F, Winkelmann C, Berendonk T, Worischka S (2015) The effects of fish kairomones and food availability on the predator avoidance behaviour of Gammarus pulex. Fund Appl Limnol 186:249-258

Taylor RB (1998) Density, biomass and productivity of animals in four subtidal rocky reef habitats: the importance of small mobile invertebrates. Mar Ecol Prog Ser 172:37-51 
Thiel M, Reise K (1993) Interaction of nemertines and their prey on tidal flats. Neth J Sea Res 31:163-172

Van Maren MJ (1975) The biology of Chaetogammarus marinus (Leach) and Eulimnogammarus obtusatus (Dahl) with some notes on other intertidal gammarid species (Crustacea, Amphipoda). Bijdr Dierkd 45:205-224

van Son TS, Thiel M (2006) Multiple predator effects in an intertidal food web. J Anim Ecol 75:25-32

Venables WN, Ripley BD (2002) Modern applied statistics with S, 4th edn. Springer, New York

Vlasblom AG (1969) A study of a population of Marinogammarus marinus (Leach) in the Oosterschelde. Neth J Sea Res 4:317-338
Werner EE, Peacor SD (2003) A review of trait-mediated indirect interactions in ecological communities. Ecology 84:1083-1100

Whalen MA, Duffy JE, Grace JB (2013) Temporal shifts in top-down vs. bottom-up control of epiphytic algae in a seagrass ecosystem. Ecology 94:510-520

Zamzow JP, Amsler CD, McClintock JB, Baker BJ (2010) Habitat choice and predator avoidance by Antarctic amphipods: the roles of algal chemistry and morphology. Mar Ecol Prog Ser 400:155-163 